DOI: 10.18276/sip.2017.50/1-01

\title{
Krzysztof Dmytrów*
}

Uniwersytet Szczeciński

\section{WPŁYW SPOSOBU NORMALIZACJI NA WYNIKI KLASYFIKACJI WARIANTÓW DECYZYJNYCH UZYSKANEJ ZA POMOCĄ UOGÓLNIONEJ MIARY ODLEGŁOŚCI}

\section{Streszczenie}

Podejmując decyzje wielokryterialne, często stosuje się takie metody, jak: TOPSIS, różne warianty Syntetycznego Miernika Rozwoju (TMAI czy TMAL) lub GDM (Generalised Distance Measure). Wszystkie te metody sprowadzają się do wyznaczenia zmiennej syntetycznej uzyskanej poprzez normalizację zmiennych, nadanie zmiennym wag i wyznaczenie ważonej odległości każdego wariantu decyzyjnego od wzorca i/lub antywzorca. Celem artykułu jest zbadanie, jak sposób normalizacji zmiennych wpłynie na ranking wariantów decyzyjnych uzyskany za pomocą Uogólnionej Miary Odległości przy danym systemie wag.

Słowa kluczowe: wielokryterialne podejmowanie decyzji, Uogólniona Miara Odległości, normalizacja

\section{Wprowadzenie}

Istnieje wiele metod podejmowania decyzji wielokryterialnych. Jedne zakładają skończoną i znaną liczbę wariantów decyzyjnych opisanych za pomocą wielu różnych, często będących wobec siebie w konflikcie kryteriów. Należy wówczas uporządkować warianty decyzyjne od najlepszego do najgorszego. Popularnymi metodami wielokryterialnego podejmowania decyzji są metody dyskretne:

\footnotetext{
Adres e-mail: krzysztof.dmytrow@usz.edu.pl
} 
- AHP (Analytical Hierarchy Process),

- ANP (Analytic Network Process),

- ELECTRE,

- PROMETHEE,

- VIKOR,

- TOPSIS (Technique for the Order of Prioritisation by Similarity to Ideal Solution).

Inne metody zakładają, że liczba wariantów może być teoretycznie nieskończona albo skończona, ale bardzo duża. Wówczas wariant decyzyjny wybiera się za pomocą metod programowania wielokryterialnego. Wśród metod postępowania w programowaniu wielokryterialnym można wyróżnić:

- leksykograficzne uporządkowanie celów,

- rozdzielenie celów na cel główny i cele poboczne,

- ważenie celów,

- wykorzystanie programowania celowego.

W artykule zbadano dyskretną metodę wielokryterialnego podejmowania decyzji. Należy zwrócić uwagę, że do podejmowania decyzji wielokryterialnych stosuje się również metody, które pierwotnie nie zostały do tego celu wymyślone, ale z powodzeniem można je zastosować. Na przykład do podejmowania decyzji na rynku kapitałowym wykorzystuje się Taksonomiczną Miarę Atrakcyjności Inwestycji (TMAI) (Tarczyński, 2001), a w procesie kompletacji produktów w magazynie-Taksonomiczną Miarę Atrakcyjności Lokalizacji (TMAL) (Dmytrów, 2015). W toku badań nad wielokryterialnymi metodami podejmowania decyzji autor sięgnął po zaproponowaną przez Walesiaka (2000) Uogólnioną Miarę Odległości (GDM - Generalised Distance Measure). Powodem zainteresowania się tą metodą był fakt, iż można ją stosować nie tylko wówczas, gdy kryteria opisujące warianty decyzyjne są przedstawione na skali metrycznej (przedziałowej lub ilorazowej), ale także na skali porządkowej (Walesiak, 2011). Dodatkowo metoda GDM pozwala uporządkować warianty decyzyjne oraz może być wykorzystana do wyznaczenia odległości od wzorca i antywzorca, na przykład w metodzie TOPSIS. W przypadku metody GDM, podobnie jak w każdej innej metodzie zakładającej wyznaczanie pewnej zmiennej syntetycznej, opieramy się na ważeniu oraz normalizacji zmiennych decyzyjnych. Autor, prowadząc swoje badania, zauważył, że oprócz wpływu na ranking wariantów decyzyjnych wag nadanych zmiennym (co jest sprawą oczywistą), duży na niego wpływ miał również sposób normalizacji zmiennych. Spowodowane jest to faktem, że unormowane zmienne przyjmują wartości z różnych przedziałów czy mają różny poziom zmienności (Kukuła, 2000). 
Celem artykułu jest zaprezentowanie wyników rangowania wariantów decyzyjnych za pomocą metody GDM, gdy zostały zastosowane różne metody normalizacji zmiennych decyzyjnych.

\section{Zastosowane metody badawcze}

Do rangowania wariantów decyzyjnych zastosowano metodę GDM opartą na uogólnionym współczynniku korelacji obejmującym współczynnik korelacji liniowej Pearsona i współczynnik korelacji $t$ Kendalla postaci (Walesiak, 2011):

$$
d_{i k}=\frac{1}{2}-\frac{\sum_{j=1}^{m} w_{j} a_{i k j} b_{k i j}+\sum_{j=1}^{m} \sum_{\substack{l=1 \\ l \neq i, k}}^{n} w_{j} a_{i l j} b_{k l j}}{2 \sqrt{\sum_{j=1}^{m} \sum_{l=1}^{n} w_{j} a_{i l j}^{2} \cdot \sum_{j=1}^{m} \sum_{l=1}^{n} w_{j} b_{k l j}^{2}}}
$$

gdzie:

$d_{i k}-$ miara odległości GDM,

$i, k, l=1, \ldots, n$ - numery obiektów,

$j=1, \ldots, m$ - numery zmiennych,

$w_{j}$ - waga $j$-tej zmiennej spełniająca warunki: $w_{j} \in\langle 0, m\rangle$ oraz $\sum_{j=1}^{m} w_{j}=m$ lub $w_{j} \in\langle 0,1\rangle$ oraz $\sum_{j=1}^{m} w_{j}=1$.

Jeżeli zmienne są mierzone na skali przedziałowej i ilorazowej, to występujące we wzorze (1) wartości $a$ i $b$ oblicza się następująco:

$$
\begin{aligned}
& a_{i p j}=x_{i j}-x_{p j} \text { dla } p=k, l, \\
& b_{k r j}=x_{k j}-x_{r j} \text { dla } r=i, l
\end{aligned}
$$

Jeżeli natomiast zmienne występują na skali porządkowej, wówczas wartości $a$ i $b$ liczy się następująco:

$$
a_{i p j}\left(b_{k r j}\right)=\left\{\begin{array}{cl}
1 & \text { jeżeże } \mathrm{x}_{\mathrm{ij}}>x_{p j}\left(x_{k j}>x_{r j}\right) \\
0 & \text { jeżeże } \mathrm{x}_{\mathrm{ij}}=x_{p j}\left(x_{k j}=x_{r j}\right) \text { dla } p=k, l, r=i, l \\
-1 & \text { jeżeże } \mathrm{x}_{\mathrm{ij}}<x_{p j}\left(x_{k j}<x_{r j}\right)
\end{array}\right.
$$


Najczęściej jest tak, że wśród zmiennych decyzyjnych występują takie, które są stymulantami (im wyższa wartość zmiennej, tym lepiej), niektóre są destymulantami (im mniejsza wartość zmiennej, tym lepiej), są też nominanty - wymagana jest nominalna wartość zmiennej. Jeżeli zmienne są mierzone na skali ilorazowej, wówczas nominantę zamieniamy na stymulantę za pomocą wzoru:

$$
x_{i j}=\frac{\min \left\{\text { nom }_{j} ; x_{i j}^{N}\right\}}{\max \left\{\text { nom }_{j} ; x_{i j}^{N}\right\}}
$$

gdzie: $x_{i j}^{N}$ - wartość $j$-tej nominanty w $i$-tym wariancie decyzyjnym, nom $_{j}$ - nominalny poziom $j$-tej zmiennej.

Dla skali przedziałowej nominantę zamieniamy na stymulantę następująco:

$$
x_{i j}=-\mid x_{i j}^{N}-\text { nom }_{j} \mid
$$

Obliczając wartość GDM, nie ma potrzeby zamieniać destymulant na stymulanty.

GDM znajduje zastosowanie do (Walesiak, 2003, s. 135):

a) wyznaczania macierzy odległości w procesie klasyfikacji obiektów;

b) konstrukcji syntetycznego miernika rozwoju;

c) wyznaczania odległości pomiędzy obiektami w innych metodach klasyfikacyjnych (np. w metodzie TOPSIS).

W niniejszym artykule miara GDM zostanie wykorzystana do konstrukcji syntetycznego miernika rozwoju. Etapy jego budowy są następujące (Walesiak, 2003, s. 137):

1. Punktem wyjścia jest macierz $\left[x_{i j}\right]$, gdzie $x_{i j}$ to wartość $j$-tej zmiennej decyzyjnej w $i$-tym obiekcie ( $i$-tym wariancie decyzyjnym).

2. Jeżeli zmienne decyzyjne są mierzone na skali przedziałowej lub ilorazowej, trzeba zamienić nominanty na stymulanty za pomocą wzoru (4) lub (5).

3. Dla zmiennych decyzyjnych mierzonych na skali przedziałowej lub ilorazowej należy dokonać ich normalizacji.

4. Zmiennym decyzyjnym należy przypisać wagi.

5. Za pomocą wzoru (1) wyznacza się odległości poszczególnych obiektów (wariantów decyzyjnych) od obiektu wzorcowego. Jest nim na ogół górny lub dolny biegun rozwoju (tzw. wzorzec i antywzorzec).

6. Obiekty (warianty decyzyjne) porządkujemy od najlepszego do najgorszego. 
Jednym z etapów budowy miary GDM jest normalizacja zmiennych. Możliwe są różne formuły normalizacyjne. Przedstawiono je w tabeli 1.

Tabela 1. Metody normalizacji zmiennych

\begin{tabular}{|c|c|}
\hline Nazwa metody i jej oznaczenie & Formuła \\
\hline Standaryzacja: $n_{1}$ & $z_{i j}=\frac{x_{i j}-\bar{x}_{j}}{s_{j}}$ \\
\hline Unitaryzacja: $n_{2}$ & $z_{i j}=\frac{x_{i j}-\bar{x}}{r_{j}}$ \\
\hline Unitaryzacja zerowana: $n_{3}$ & $z_{i j}=\frac{\left[x_{i j}-\min _{i}\left\{x_{i j}\right\}\right]}{r_{j}}$ \\
\hline Normalizacja w przedziale $\langle-1 ; 1\rangle: n_{4}$ & $z_{i j}=\frac{x_{i j}-\bar{x}}{\max _{i}\left|x_{i j}-\bar{x}_{j}\right|}$ \\
\hline \multirow{6}{*}{ Przekształcenia ilorazowe: $n_{5}-n_{10}$} & $z_{i j}=\frac{x_{i j}}{s_{j}}$ \\
\hline & $z_{i j}=\frac{x_{i j}}{r_{j}}$ \\
\hline & $z_{i j}=\frac{x_{i j}}{\max _{i}\left\{x_{i j}\right\}}$ \\
\hline & $z_{i j}=\frac{x_{i j}}{\bar{x}_{j}}$ \\
\hline & $z_{i j}=\frac{x_{i j}}{\sum_{i=1}^{n} x_{i j}}$ \\
\hline & $z_{i j}=\frac{x_{i j}}{\sqrt{\sum_{i=1}^{n} x_{i j}^{2}}}$ \\
\hline
\end{tabular}

Źródło: Walesiak (2011), s. 19. 
Należy zauważyć, że przekształcenia ilorazowe można stosować wyłącznie wtedy, gdy zmienne są mierzone na skali ilorazowej, a pozostałe można stosować zarówno dla skali przedziałowej, jak i ilorazowej. Charakterystyki rozkładów znormalizowanych zmiennych uzyskanych za pomocą formuł przedstawionych w tabeli 1 znajdują się w pracy Walesiaka (2011, s. 20).

\section{Rankingi wariantów decyzyjnych przy wyborze komputera}

Dane do przykładu numerycznego pochodzą ze strony http://www.pcmag.com/ article2/0,2817,2369981,00.asp. Problem decyzyjny dotyczy wyboru komputera opisanego za pomocą jedenastu zmiennych decyzyjnych ${ }^{1}$. Analizowane komputery były opisane za pomocą następujących zmiennych:

- cena w USD (destymulanta) $-x_{1}$,

- ilość pamięci RAM w GB (stymulanta) $-x_{2}$,

- pojemność dysku SSD w GB (stymulanta) - $x_{3}$,

- przekątna ekranu w calach (nominanta o wartości nominalnej 14 cali) $-x_{4}$,

- rozdzielczość ekranu zamieniona na liczbę pikseli (stymulanta) $-x_{5}$,

- waga w kilogramach (destymulanta) $-x_{6}$,

- czas pracy na akumulatorze w minutach (stymulanta) $-x_{7}$,

- wyniki testów wydajności:

PCMark 8 Work Conventional w punktach (stymulanta) $-x_{8}$,

CineBench w punktach (stymulanta) $-x_{9}$,

Photoshop w sekundach (destymulanta) $-x_{10}$,

3DMark Cloud Gate w punktach (stymulanta) $-x_{11}$.

Przyjęcie zmiennej $x_{4}$ (przekątnej ekranu) za nominantę o wartości nominalnej 14 cali było czysto subiektywne. Autor uznał przekątną ekranu równą 14 cali za rozsądny kompromis pomiędzy komfortem pracy a mobilnością sprzętu. Podobnie jak we wspomnianym złożonym artykule, tutaj także pogrupowano zmienne w kryteria:

a) kryterium Cena, zmienna cena;

b) kryterium Wydajność, zmienne: PCMark 8 Work Conventional, CineBench, Photoshop oraz 3DMark Cloud Gate;

c) kryterium Mobilność, zmienne: przekątna ekranu, waga oraz czas pracy na akumulatorze;

1 Dane te zostały wykorzystane w referacie wygłoszonym na konferencji „Modelowanie Preferencji a Ryzyko '17' (Dmytrów, 2017). 
d) kryterium Wyposażenie, zmienne: ilość pamięci RAM w GB, pojemność dysku SSD w GB oraz rozdzielczość ekranu zamieniona na liczbę pikseli.

Celem wyodrębnienia poszczególnych kryteriów było nadanie wag odpowiednim zmiennym, zakładając, że dla kupującego najważniejsza jest cena, wydajność, mobilność albo wyposażenie. Parametry charakteryzujące analizowane komputery przedstawiono w tabeli 2.

Tabela 2. Parametry charakteryzujące analizowane komputery.

\begin{tabular}{|l|r|r|r|c|c|c|c|c|c|c|r|}
\hline \multicolumn{1}{|c|}{ Komputery/zmienne } & \multicolumn{1}{c|}{$x_{1}$} & \multicolumn{1}{c|}{$x_{2}$} & $x_{3}$ & $x_{4}$ & $x_{5}$ & $x_{6}$ & $x_{7}$ & $x_{8}$ & $x_{9}$ & $x_{10}$ & $x_{11}$ \\
\hline Lenovo Yoga 910 & 1199,99 & 8 & 256 & 13,9 & 2,074 & 1,365 & 1288 & 3197 & 349 & 215 & 6815 \\
\hline Razer Blade Pro & 2099,99 & 32 & 512 & 17,3 & 8,294 & 3,502 & 228 & 2838 & 681 & 183 & 25439 \\
\hline New Razer Blade Stealth & 999,99 & 16 & 256 & 12,5 & 3,686 & 1,315 & 560 & 3032 & 354 & 221 & 6401 \\
\hline Asus ZenBook 3 & 959,00 & 16 & 512 & 12,5 & 2,074 & 0,894 & 727 & 3228 & 332 & 288 & 6132 \\
\hline $\begin{array}{l}\text { Dell Inspiron 15 7000 } \\
\text { Gaming }\end{array}$ & 799,99 & 8 & 256 & 15,6 & 2,074 & 2,649 & 661 & 3258 & 502 & 212 & 15976 \\
\hline Dell XPS 13 Touch & 1184,11 & 8 & 256 & 13,3 & 5,760 & 1,356 & 642 & 2769 & 342 & 222 & 6761 \\
\hline Lenovo ThinkPad X260 & 949,99 & 8 & 256 & 12,5 & 2,074 & 1,374 & 645 & 2995 & 313 & 275 & 5452 \\
\hline Microsoft Surface Book & 1999,99 & 16 & 1024 & 13,5 & 6,000 & 1,647 & 1156 & 2735 & 326 & 243 & 8980 \\
\hline
\end{tabular}

Źródło: opracowanie własne na podstawie danych ze strony http://www.pcmag.com/artice2/0,2817,2369981,00.asp.

Z danych zawartych w tabeli 2 widać, że nawet bez zastosowania żadnych mniej lub bardziej zaawansowanych metod można wyróżnić różne grupy komputerów. Na przykład komputery Razer Blade Pro i Microsoft Surface Book są drogie, ale jednocześnie dobrze wyposażone i wydajne. Komputery: Lenowo Yoga 910, Microsoft Surface Book, Asus ZenBook czy Dell XPS 13 Touch są lekkie, mobilne i długo działają na baterii.

Po zamianie według wzoru (4) zmiennej $x_{4}$ na stymulantę obliczono niektóre parametry rozkładu wszystkich zmiennych decyzyjnych. Przedstawiono je w tabeli 3. 
Tabela 3. Wybrane parametry rozkładu zmiennych decyzyjnych

\begin{tabular}{|c|c|c|c|c|c|c|c|c|c|c|c|}
\hline & $x_{1}$ & $x_{2}$ & $x_{3}$ & $x_{4}$ & $x_{5}$ & $x_{6}$ & $x_{7}$ & $x_{8}$ & $x_{9}$ & $x_{10}$ & $x_{11}$ \\
\hline $\bar{x}$ & 1274,13 & 14 & 416 & 0,912 & 4,00 & 1,76 & 738,38 & 3006,5 & 399,88 & 232,38 & 10244,5 \\
\hline $\mathrm{S}$ & 464,60 & 7,75 & 253,99 & 0,05 & 2,25 & 0,81 & 314,83 & 196,18 & 119,96 & 32,43 & 6556,21 \\
\hline$V_{s}[\%]$ & 36,46 & 55,33 & 61,06 & 5,83 & 56,18 & 45,97 & 42,64 & 6,53 & 30,00 & 13,96 & 64,00 \\
\hline $\mathrm{A}$ & 0,994 & 1,424 & 1,667 & $-0,311$ & 0,739 & 1,251 & 0,417 & $-0,079$ & 1,651 & 0,443 & 1,588 \\
\hline $\mathrm{R}$ & 1300 & 24 & 768 & 0,18 & 6,22 & 2,61 & 1060 & 523 & 368 & 105 & 19987 \\
\hline$R / \bar{x}[\%]$ & 102,03 & 171,43 & 184,62 & 20,14 & 155,35 & 147,96 & 143,56 & 17,40 & 92,03 & 45,19 & 195,10 \\
\hline
\end{tabular}

$\bar{x}$ - wartość średnia zmiennej decyzyjnej,

$S$ - odchylenie standardowe zmiennej decyzyjnej,

$V_{s}$ - współczynnik zmienności zmiennej decyzyjnej,

$A$ - klasyczny współczynnik asymetrii zmiennej decyzyjnej,

$R$ - rozstęp zmiennej decyzyjnej,

$R / \bar{x}$ - udział rozstępu w wartości średniej zmiennej decyzyjnej.

Źródło: opracowanie własne na podstawie tabeli 2.

Widać, że rozkłady badanych zmiennych decyzyjnych różnią się od siebie często bardzo mocno. O ile nie ma sensu porównywać miar absolutnych, takich jak: średnia, odchylenie standardowe czy rozstęp, to jak najbardziej można to zrobić z miarami niemianowanymi. Należy na samym początku zauważyć, że wśród badanych zmiennych zmienna $x_{4}$ już jest zmienną przekształconą. Jej wartość średnia mówi o tym, że średnia przekątna ekranu w badanej grupie komputerów była niższa od wartości nominalnej wynoszącej 14 cali. Największą zmiennością charakteryzowały się: ilość pamięci RAM, pojemność dysku SSD, liczba pikseli ekranu oraz wydajność komputera w grach, czyli wyniki testu 3DMark Cloud Gate. Najmniejszą zaś zmienność posiadały następujące zmienne decyzyjne: przekątna ekranu, wynik testu PCMark 8 Work Conventional oraz wynik testu Photoshop.

Pojemność dysku SSD, ilość pamięci RAM, wyniki testu CineBench oraz 3DMark Cloud Gate charakteryzowały się bardzo silną asymetrią prawostronną, przekątna ekranu posiadała umiarkowaną asymetrię lewostronną, a wyniki testu PCMark 8 Work Conventional były zmienną o rozkładzie symetrycznym.

$\mathrm{W}$ artykule przyjęto kilka kombinacji wag spełniających warunek $\sum_{j=1}^{m} w_{j}=m$. Założono, że wszystkie zmienne decyzyjne są jednakowo ważne oraz że decydent może uznać za najważniejsze kryterium ceny, wydajności, mobilności oraz wyposażenia. W takim przypadku przyjęto subiektywnie, że waga zmiennych tworzących dane kryterium będzie około trzech razy większa niż waga pozostałych zmiennych. Wyniki rangowania wariantów decyzyjnych dla poszczególnych kombinacji wag i metod normalizacji zmiennych decyzyjnych przedstawiono w tabeli 4 . 
Tabela 4. Wyniki rangowania wariantów decyzyjnych

\begin{tabular}{|c|c|c|c|c|c|c|c|c|c|c|}
\hline Wyszczególnienie & $n_{1}$ & $n_{2}$ & $n_{3}$ & $n_{4}$ & $n_{5}$ & $n_{6}$ & $n_{7}$ & $n_{8}$ & $n_{9}$ & $n_{10}$ \\
\hline Wagi równe & 1 & 1 & 1 & 1 & 1 & 1 & 1 & 1 & 1 & 1 \\
\hline Lenovo Yoga 910 & 2 & 4 & 4 & 3 & 2 & 4 & 7 & 7 & 7 & 7 \\
\hline Razer Blade Pro & 3 & 1 & 1 & 1 & 3 & 1 & 2 & 2 & 2 & 2 \\
\hline New Razer Blade Stealth & 5 & 5 & 5 & 5 & 5 & 5 & 5 & 5 & 5 & 4 \\
\hline Asus ZenBook 3 & 6 & 6 & 6 & 6 & 6 & 6 & 3 & 3 & 3 & 3 \\
\hline Dell Inspiron 157000 Gaming & 4 & 3 & 3 & 4 & 4 & 3 & 4 & 4 & 4 & 5 \\
\hline Dell XPS 13 Touch & 7 & 7 & 7 & 7 & 7 & 7 & 6 & 6 & 6 & 6 \\
\hline Lenovo ThinkPad X260 & 8 & 8 & 8 & 8 & 8 & 8 & 8 & 8 & 8 & 8 \\
\hline Microsoft Surface Book & 1 & 2 & 2 & 2 & 1 & 2 & 1 & 1 & 1 & 1 \\
\hline Kryterium cena, wagi & 2,585 & 0,842 & 0,842 & 0,842 & 0,842 & 0,842 & 0,842 & 0,842 & 0,842 & 0,842 \\
\hline Lenovo Yoga 910 & 2 & 3 & 3 & 2 & 2 & 3 & 7 & 7 & 7 & 7 \\
\hline Razer Blade Pro & 7 & 2 & 2 & 3 & 7 & 2 & 1 & 1 & 1 & 1 \\
\hline New Razer Blade Stealth & 3 & 4 & 4 & 4 & 3 & 4 & 5 & 5 & 5 & 5 \\
\hline Asus ZenBook 3 & 4 & 5 & 5 & 6 & 4 & 5 & 3 & 3 & 3 & 3 \\
\hline Dell Inspiron 157000 Gaming & 1 & 1 & 1 & 1 & 1 & 1 & 4 & 4 & 4 & 4 \\
\hline Dell XPS 13 Touch & 6 & 7 & 7 & 7 & 6 & 7 & 6 & 6 & 6 & 6 \\
\hline Lenovo ThinkPad X260 & 8 & 8 & 8 & 8 & 8 & 8 & 8 & 8 & 8 & 8 \\
\hline Microsoft Surface Book & 5 & 6 & 6 & 5 & 5 & 6 & 2 & 2 & 2 & 2 \\
\hline Kryterium wydajność, wagi & 0,572 & 0,572 & 0,572 & 0,572 & 0,572 & 0,572 & 0,572 & 1,749 & 1,749 & 1,749 \\
\hline Lenovo Yoga 910 & 3 & 3 & 3 & 3 & 3 & 3 & 4 & 7 & 7 & 7 \\
\hline Razer Blade Pro & 1 & 1 & 1 & 1 & 1 & 1 & 1 & 1 & 1 & 1 \\
\hline New Razer Blade Stealth & 4 & 4 & 4 & 4 & 4 & 4 & 5 & 5 & 5 & 5 \\
\hline Asus ZenBook 3 & 7 & 6 & 6 & 6 & 7 & 6 & 7 & 4 & 4 & 4 \\
\hline Dell Inspiron 157000 Gaming & 2 & 2 & 2 & 2 & 2 & 2 & 2 & 3 & 3 & 3 \\
\hline Dell XPS 13 Touch & 6 & 7 & 7 & 7 & 6 & 7 & 6 & 6 & 6 & 6 \\
\hline Lenovo ThinkPad X260 & 8 & 8 & 8 & 8 & 8 & 8 & 8 & 8 & 8 & 8 \\
\hline Microsoft Surface Book & 5 & 5 & 5 & 5 & 5 & 5 & 3 & 2 & 2 & 2 \\
\hline Kryterium mobilność, wagi & 0,649 & 0,649 & 0,649 & 1,936 & 0,649 & 1,936 & 1,936 & 0,649 & 0,649 & 0,649 \\
\hline Lenovo Yoga 910 & 1 & 2 & 2 & 1 & 1 & 2 & 2 & 3 & 3 & 3 \\
\hline Razer Blade Pro & 8 & 7 & 7 & 7 & 8 & 7 & 4 & 4 & 4 & 4 \\
\hline New Razer Blade Stealth & 5 & 6 & 6 & 6 & 5 & 6 & 6 & 6 & 6 & 6 \\
\hline Asus ZenBook 3 & 4 & 3 & 3 & 5 & 4 & 3 & 3 & 2 & 2 & 2 \\
\hline Dell Inspiron 157000 Gaming & 6 & 5 & 5 & 3 & 6 & 5 & 7 & 7 & 7 & 7 \\
\hline Dell XPS 13 Touch & 3 & 4 & 4 & 4 & 3 & 4 & 5 & 5 & 5 & 5 \\
\hline Lenovo ThinkPad X260 & 7 & 8 & 8 & 8 & 7 & 8 & 8 & 8 & 8 & 8 \\
\hline Microsoft Surface Book & 2 & 1 & 1 & 2 & 2 & 1 & 1 & 1 & 1 & 1 \\
\hline Kryterium wyposażenie, wagi & 0,649 & 1,936 & 1,936 & 0,649 & 1,936 & 0,649 & 0,649 & 0,649 & 0,649 & 0,649 \\
\hline Lenovo Yoga 910 & 6 & 7 & 7 & 6 & 6 & 7 & 7 & 7 & 7 & 7 \\
\hline Razer Blade Pro & 2 & 1 & 1 & 1 & 2 & 1 & 1 & 2 & 2 & 2 \\
\hline New Razer Blade Stealth & 4 & 4 & 4 & 3 & 4 & 4 & 4 & 4 & 4 & 4 \\
\hline Asus ZenBook 3 & 3 & 3 & 3 & 4 & 3 & 3 & 3 & 3 & 3 & 3 \\
\hline Dell Inspiron 157000 Gaming & 7 & 6 & 6 & 7 & 7 & 6 & 6 & 6 & 6 & 6 \\
\hline Dell XPS 13 Touch & 5 & 5 & 5 & 5 & 5 & 5 & 5 & 5 & 5 & 5 \\
\hline Lenovo ThinkPad X260 & 8 & 8 & 8 & 8 & 8 & 8 & 8 & 8 & 8 & 8 \\
\hline Microsoft Surface Book & 1 & 2 & 2 & 2 & 1 & 2 & 2 & 1 & 1 & 1 \\
\hline
\end{tabular}

Źródło: opracowanie własne. 
Zakładając, że wszystkie zmienne decyzyjne mają takie same wagi, na ogół pierwsze dwa miejsca zajmują komputery Razer Blade Pro oraz Microsoft Surface Book. Niezależnie od przyjętego sposobu normalizacji ostatnie miejsce w rankingu zajmował Lenovo ThinkPad X260. Najbardziej różni się pozycja komputera Lenovo Yoga 910 - przy zastosowaniu standaryzacji (metoda $n_{1}$ ) oraz pierwszej metody z grupy przekształceń ilorazowych $\left(n_{5}\right)$ zajmował on drugą pozycję, a przy pozostałych przekształceniach ilorazowych spadał na przedostatnie miejsce.

W przypadku, gdy największą wagę ma cena, różnice w klasyfikacji wariantów decyzyjnych są niezwykle interesujące. Okazuje się, że najtańszy komputer - Dell Inspiron 157000 Gaming - zajął pierwsze miejsce w rankingu, gdy zastosowano metody normalizacji od $n_{1}$ do $n_{6}$. Przy wykorzystaniu pozostałych $\operatorname{metod}\left(\operatorname{od} n_{7}\right.$ do $\left.n_{10}\right)$ pierwsze miejsce w rankingu zajął Razer Blare Pro, a więc najdroższy komputer, a drugie miejsce - Microsoft Surface Book, czyli drugi najdroższy. Zapewne jest tak dlatego, że komputery te są również wydajne i dobrze wyposażone, przez co zajmują wyższą pozycję w rankingu. Co ciekawe, drugi najtańszy komputer - Lenovo ThinkPad X260 - zajmował zawsze ostatnie miejsce, niezależnie od zastosowanej metody normalizacji.

Jeżeli założymy, że najważniejszym kryterium decyzyjnym jest wydajność, wówczas rankingi uzyskane przy zastosowaniu różnych metod normalizacji są najmniej zaskakujące. W każdym przypadku pierwsze miejsce zajmował Razer Blade Pro, który jest zdecydowanie najmocniejszym komputerem w zestawieniu. Drugie miejsce miał albo Dell Inspiron 157000 Gaming (dla metod od $n_{1}$ do $n_{7}$ ), albo Microsoft Surface Book (dla metod od $n_{8}$ do $n_{10}$ ). Ponownie, jak w poprzednich rankingach, ostatnie miejsce w zestawieniu przypadło Lenovo ThinkPad X260.

Rankingi uzyskane przy założeniu, że najważniejszym kryterium wyboru komputera jest mobilność, były dość oczywiste. Pierwsze miejsca zajmowały komputery Microsoft Surface Book (przy zastosowaniu metod $n_{2}, n_{3}$ oraz $n_{6}-n_{10}$ ) oraz Lenovo Yoga 910 (dla pozostałych metod normalizacji). Są to komputery lekkie, najdłużej pracujące na jednym naładowaniu akumulatora oraz posiadające przekątne ekranu najbardziej zbliżone do optymalnych 14 cali. Co ciekawe, najmniej mobilny komputer - Razer Blade Pro - zajął ostatnie miejsca jedynie dla metod $n_{1}$ oraz $n_{5}$. W pozostałych przypadkach ostatnie miejsca okupował, podobnie jak w poprzednich rankingach, Lenovo ThinkPad X260.

Jeżeli przyjmiemy, że najważniejsze dla kupującego jest wyposażenie komputerów, to dwa pierwsze miejsca w rankingu zajmowały zawsze Razer Blade Pro albo Microsoft Surface Book, co jest oczywiste, ponieważ były to najlepiej wyposażone komputery. Ostatnie miejsce zajmował zawsze Lenovo ThinkPad X260. 


\section{Podsumowanie}

W artykule dokonano porównania wyników rangowania wariantów decyzyjnych za pomocą GDM przy zastosowaniu różnych metod normalizacji zmiennych decyzyjnych dla różnych kombinacji wag. Okazało się, że zastosowana metoda normalizacji dla danej kombinacji wag często ma duży wpływ na pozycję danego komputera (wariantu decyzyjnego) w rankingu. Zdarzało się, że różnice w pozycji komputera $\mathrm{w}$ rankingu dla jednej kombinacji wag sięgały czasami sześciu pozycji (na osiem analizowanych komputerów). Tak było dla najdroższego w zestawieniu komputera - Razera Blade Pro dla kombinacji wag, w której najważniejsza była cena. Mimo że jest to najdroższy komputer w zestawieniu, dla niektórych metod normalizacji zajął pierwsze miejsce, podczas gdy dla innych - przedostatnie, czyli siódme. Może to być spowodowane tym, że inne parametry miał na tak wysokim poziomie, że zawyżały jego pozycję w rankingu. Dalszym etapem badań będzie sprawdzenie, dlaczego działo się tak dla niektórych metod normalizacji, a dla innych nie. Zostanie też porównane rangowanie wariantów decyzyjnych za pomocą metody GDM dla różnych metod normalizacji z rangowaniem uzyskanym dla innych metod, na przykład TOPSIS czy dla SMR uzyskanego przy zastosowaniu odległości euklidesowych.

\section{Literatura}

Dmytrów, K. (2015). Taksonomiczne wspomaganie wyboru lokalizacji w procesie kompletacji produktów. Studia Ekonomiczne. Zeszyty Naukowe Uniwersytetu Ekonomicznego w Katowicach, 248, 17-30.

Dmytrów, K. (2017). Zastosowanie Uogólnionej Miary Odległości do podejmowania decyzji wielokryterialnych. Referat na XI ogólnopolskiej Konferencji Naukowej „Modelowanie Preferencji a Ryzyko '17”' (Ustroń, 2-4 kwietnia 2017 r.).

http://www.pcmag.com/article2/0,2817,2369981,00.asp (10.03.2017).

Kukuła, K. (2000). Metoda unitaryzacji zerowanej. Warszawa: Wydawnictwo Naukowe PWN. Tarczyński, W. (2001). Rynki kapitatowe cz. I. Metody ilościowe. Warszawa: Placet.

Walesiak, M. (2000). Propozycja uogólnionej miary odlegtości w statystycznej analizie wielowymiarowej. Referat na konferencję naukową nt. „Statystyka regionalna w służbie samorządu lokalnego i biznesu" (Kiekrz k. Poznania, 5-7 czerwca 2000 r.).

Walesiak, M. (2003). Uogólniona Miara Odległości GDM jako syntetyczny miernik rozwoju w metodach porządkowania liniowego. Prace Naukowe Akademii Ekonomicznej we Wrocławiu, 988, Taksonomia 10, Klasyfikacja i analiza danych - teoria i zastosowania, 134-144. 
Walesiak, M. (2011). Uogólniona Miara Odległości GDMw statystycznej analizie wielowymiarowej z wykorzystaniem programu $R$. Wrocław: Wyd. UE we Wrocławiu.

\title{
IMPACT OF THE NORMALISATION METHOD ON THE RESULTS OF CLASSIFICATION OF DECISION VARIANTS BY MEANS OF THE GENERALISED DISTANCE MEASURE
}

\begin{abstract}
In the Multi-Criteria Decision Making problems, methods like TOPSIS, variants of the Synthetic Measure of Development or Generalised Distance Method are used. All of them are resolved by creating the synthetic variable, obtained by normalisation of variables and calculation of weighed distance of every decision variant from the pattern or (and) anti-pattern. The goal of the article is the analysis, how the normalisation method influences the ranking of decision variants obtained by means of the Generalised Distance Method.
\end{abstract}

Translated by Krzysztof Dmytrów

Keywords: Multi-Criteria Decision Making, Generalised Distance Method, normalisation JEL Codes: C38, C44 